\title{
ENTRELAÇAMENTO ENTRE OS VIVOS E OS MORTOS EM TERRA SONÂMBULA E A VARANDA DO FRANGIPANI
}

\author{
Josiane Souza Pires* \\ Luiz Otávio de Magalhães*
}

RESUMO: Neste artigo buscamos apresentar uma leitura das obras Terra Sonâmbula e $A$ varanda do Frangipani, do autor moçambicano Mia Couto, enfatizando o entrelaçamento entre os vivos e os mortos, com destaque para as cerimônias fúnebres. As duas narrativas trazem questões instigantes sobre cerimônias e os cuidados que devem ser dados aos mortos. A morte aparece não apenas como um fenômeno físico, mas como místico e espiritual. Busca-se refletir como essas percepções da morte estão presentes no universo moçambicano. Como aporte teórico, utilizamos as leituras de Ferreira (2007), Gomes (2016) e Otinta (2008).

PALAVRAS-CHAVE: Cerimônias; Mia Couto; Mortos; Vivos.

Encheram a terra de fronteiras, carregaram o céu de bandeiras. Mas só há duas nações - a dos vivos e a dos mortos. Mia Couto

Várias obras de Mia Couto são permeadas pela questão da morte e dos espíritos, das cerimônias fúnebres e das relações entre a morte e o sonho. A varanda do Frangipani é narrada por um morto, que não teve uma morte digna. Em Terra Sonâmbula, pode se dizer

\footnotetext{
* Mestranda Em Letras: Cultura, Educação e Linguagens pela Universidade Estadual do Sudoeste da Bahia (Uesb). ** Doutor em História Social pela Universidade de São Paulo (Usp). Professor Titular da Universidade Estadual do Sudoeste da Bahia (Uesb).
} 
que os cadernos de Kindzu cumprem a função de um espírito. A morte e os sonhos também aparecem de forma bastante contundente nos capítulos em que se faz presente o velho Taímo. Em A varanda do Frangipani, Ermelindo Mucanga começa a narrativa falando sobre os desmerecimentos de sua morte.

Me faltou cerimónia e tradição quando me enterraram. Não tive sequer quem me dobrasse os joelhos. A pessoa deve sair do mundo tal igual como nasceu, enrolada em poupança de tamanho. Os mortos devem ter a discrição de ocupar pouca terra. Mas eu não ganhei acesso a cova pequena. Minha campa estendeu-se por minha inteira dimensão, do extremo à extremidade. Ninguém me abriu as mãos quando meu corpo ainda esfriava. Transitei-me com os punhos fechados, chamando maldição sobre os viventes. E ainda mais: não me viraram o rosto a encarar os montes Nkuluvumba. Nós, os $\mathrm{Mu}-$ cangas, temos obrigações para com os antigamentes. Nossos mortos olham o lugar onde a primeira mulher saltou a lua, arredondada de ventre e alma (COUTO, 2007a, p. 09).

Nessa fala do morto Ermelindo Mucanga, percebem-se vários fatores relacionados com as cerimônias fúnebres. A maneira como o corpo deveria ser coberto, o tamanho da cova, a posição como deve ser enterrado. São vários os detalhes que estão envoltos na cerimônia fúnebre. Todos esses “desmerecimentos” fizeram com que sua alma não encontrasse a paz.

Não foi só o devido funeral que me faltou. Os desleixos foram mais longe: como eu não tivesse outros bens me sepultaram com minha serra e o martelo. Não o deviam ter feito. Nunca se deixa entrar em tumba nenhuns metais. Os ferros demoram mais a apodrecer que os ossos do falecido. E ainda pior: coisa que brilha é chamatriz da maldição. Com tais inutensílios, me arrisco a ser um desses defuntos estragadores do mundo (COUTO, 2007a, p. 09-10).

O morto tinha sido enterrado com utensílios de metal, o que para ele, era motivo de maldição. Outra preocupação importante para os personagens da narrativa de Mia Couto é ser enterrado fora do lugar em que nasceu. "Todas estas atropelias sucederam porque morri fora do meu lugar. Trabalhava fora da minha vila natal" (COUTO, 2007a, p. 10). Essa questão do lugar de origem vai aparecer em vários momentos da narrativa, como 
no capítulo do velho português, em que os velhos do asilo tinham pena do português porque iria morrer fora de seu lugar. Todos esses detalhes na cerimônia fazem com que o morto não encontre a paz e nem se torne um espírito sossegado, e sim fique vagando sem paradeiro.

Como não me apropriaram funeral fiquei em estado de xipoco, essas almas que vagueiam de paradeiro em desparadeiro. Sem ter sido cerimoniado acabei um morto desencontrado da sua morte. Não ascenderei nunca ao estado de xicuembo, que são os defuntos definitivos, com direito a serem chamados e amados pelos vivos. Sou desses mortos a quem não cortaram o cordão desumbilical. Faço parte daqueles que não são lembrados. Mas não ando por aí, pandemoniando os vivos. Aceitei a prisão da cova, me guardei no sossego que compete aos falecidos (COUTO, 2007a, p. 10).

Ermelindo foi enterrado ao lado de uma frangipaneira, isso ainda o consolava, ser perfumado pelas flores do Frangipani. Mas, eis que um dia vieram mexer em sua cova; querem desenterrá-lo para torná-lo herói, pois Ermelindo morrera em combate contra o ocupante colonial. Precisavam dos restos mortais de um de sua raça, tribo e região, porém, Ermelindo não queria ser herói, não foi amado enquanto vivo, não queria ser glorificado agora. Ermelindo não queria voltar a viver, ainda mais que o país estava em ruínas. “- Não lhe apetece ficar vivo outra vez? - Não. Como está a minha terra, não me apetece” (COUTO, 2007a, p. 13).

Ermelindo procura o pangolin, mamífero coberto de escamas que se alimenta de formigas, para saber o que ele deveria fazer para fugir dessa "missão" de se tornar um herói. Em Moçambique, acredita-se que o pangolin habita os céus, descendo à terra para transmitir aos chefes tradicionais as novidades sobre o futuro. A solução encontrada foi que Ermelindo deveria remorrer, infiltrar-se no corpo de uma pessoa que estivesse próximo da morte. O morto ainda duvidava: era realmente uma tarefa para se cumprir? Mas, logo o morto já se ocupava pela antecipação da viagem ao mundo dos vivos. Assim, Ermelindo vai se infiltrar no corpo do policial Izidine Naíta, que vai para um asilo de velhos investigar 
a misteriosa morte do inspetor do asilo, Vasto Excelêncio. O morto chegou a sonhar e em seu sonho imaginou uma cerimônia digna para sua morte.

Me enchi tanto desta vontade que até sonhei sem chuva nem noite. $\mathrm{O}$ que sonhei? Sonhei que me enterravam devidamente, como mandam nossas crenças. Eu falecia sentado, queixo na varanda dos joelhos. Descia à terra nessa posição, meu corpo assentava sobre areia que haviam retirado de um morro de muchém. Areia viva, povoada de andanças. Depois me deitavam terra com suavidade de quem veste um filho. Não usavam pás. Apenas serviço de mãos. Paravam quando a areia me chegava aos olhos. Então, espetavam à minha volta paus de acácias. Tudo em aptidão de ser flor. E para convocar a chuva me cobriam de terra molhada. Assim eu me aprendia: um vivo pisa o chão, um morto é pisado pelo chão (COUTO, 2007a, p. 15).

A descrição do sonho pelo morto é permeada de emoção e sentimento. Os detalhes de um devido funeral, a posição do corpo, a maneira como a terra é jogada no cadáver com as mãos. Essas questões aparecem com muita frequência no desenrolar de toda a narrativa e também em outras obras de Mia Couto. A morte e seu fim e o destino dos vivos são entrelaçados por mistérios e ritos.

E sonhei ainda mais: após a minha morte, todas as mulheres do mundo dormiam ao relento. Não era apenas a viúva que estava interdita a abrigar-se, como é hábito da nossa crença. Não. Era como se todas as mulheres tivessem, em mim, perdido o esposo. Todas estavam sujas por minha morte. O luto se estendia por todas as aldeias como um cacimbo espesso. As lamparinas iluminavam o milho, mãos trémulas passavam com o cadinho do fogo entre os espigueirais. Limpavam-se os campos dos maus-olhados (COUTO, 2007a, p. 15).

As cerimônias fúnebres envolvem outras cerimônias. Após a morte de alguém há alguns ritos que não devem ser feitos, a maneira como as pessoas devam se comportar. $\mathrm{Na}$ citação acima, percebe-se que a viúva deveria dormir ao relento em respeito ao morto.

No terceiro capítulo, “A confissão de Navaia”, também aparecem fatos relacionados a cerimônias fúnebres. Navaia Caetano era uma criança velha, que sofria uma maldição, 
a doença da idade antecipada. Um menino que envelheceu logo após a nascença. Um dia, Nãozinha, a feiticeira, resolveu fazer uma cerimônia para aliviar os sofrimentos da criança velha. Era preciso sossegar o espírito da mãe de Navaia.

\begin{abstract}
Chamou-me para me dizer que iria aprontar uma cerimónia para agarrar o mupfukwa, esse mau espírito que me perseguia. Era preciso um animal, carecia-se de fazer descer o sangue à terra. Mas animal, ali, onde eu iria desencantar? Falei com a coruja e lhe encomendei peça viva. Nessa noite, me coube uma garça em estado moribundo. Despescoçámos a garça. Contudo, o sangue da ave era tão leve que não tombou no soalho. Foi preciso apanhá-lo junto do pescoço. A cerimónia estava pronta a ter início. Nãozinha falou claro: o espírito de minha mãe que exigia satisfação (COUTO, 2007a, p. 32-33).
\end{abstract}

Nem todos compreendiam o significado dessas cerimônias. O policial Izidine Naíta, que estava investigando os velhos, não entendia a significação de determinadas cerimônias. O policial não conhecia as crenças, estudara na Europa e voltara a Moçambique anos depois da Independência; era um desconhecido. Esse afastamento da cidade limitou o seu conhecimento da cultura, das línguas, dos pequenos acontecimentos que figuram a alma de um povo.

Também no quinto capítulo, “A confissão do velho português”, aparece o tema do local devido de sepultamento de um morto. Domingos Mourão, ou Xidimingo, era um velho português, que há muito tempo morava em Moçambique. Um dia, numa conversa entre o velho Nhonhoso e Xidimingo surgiu a questão do enterro:

— Você, Xidimingo, pertence a Moçambique, este país lhe pertence. Isso nem é duvidável. Mas não lhe traz um arrepio ser enterrado aqui?

- Aqui, onde?, perguntei.

— Num cemitério daqui, de Moçambique? Eu encolhi os ombros. Nem cemitério eu não teria, ali no asilo. Mas Nhonhoso insistiu:

- É que os seus espíritos não pertencem a este lugar. Enterrado aqui, você será um morto sem sossego (COUTO, 2007a, p. 46-47). 
Percebe-se mais uma vez como a tradição e crença da cerimônia são importantes para aquele povo. $\mathrm{O}$ velho português, por pertencer a outra tradição, nem se importa muito com essa questão de ser enterrado fora de casa, mas os da terra preservam essa visão do sossego dos espíritos. A mesma temática aparece no capítulo "A confissão de Nhonhoso":

Voltei atrás e me sentei ao lado do português. Senti, naquele instante, tanta pena dele. O homenzito iria morrer aqui, longe dos antepassados. Seria enterrado em terra alheia. Ele, sim, estava condenado à mais terrível das solidões: ficar longe dos seus mortos sem que, deste lado da vida, houvesse familiar que lhe deitasse cuidados. Nossos deuses estão aqui perto. O Deus dele está longe, para além das vistas e das visitas (COUTO, 2007a, p. 66).

Ser enterrado fora de casa, longe dos espíritos era considerado a pior das solidões. Não haveria um familiar que lhe deitasse cuidados, fosse lhe visitar, seus deuses também estariam longe. No nono capítulo, “A confissão de Nãozinha”, esta fala da morte de seu pai e de alguns detalhes do funeral. Ela era criança, não podia ver seu pai, pois nesse tempo era interditado às crianças verem os falecidos. "Você sabe, a morte é como uma nudez: depois de se ver quer-se tocar. De meu pai não ficou nenhuma imagem, nenhuma sobra de sua presença. Seguindo os antigos mandos, todos os pertences, incluindo fotografias, eram enterrados com o defunto" (COUTO, 2007a, p. 80). Assim, o romance vai se constituindo de histórias dentro de histórias, trazendo mitos, ritos, crenças e várias tradições em relação às cerimônias fúnebres.

Também em Terra Sonâmbula, as cerimônias fúnebres merecem destaque. Essas cerimônias vão aparecer principalmente nos cadernos de Kindzu, nas narrativas relacionadas a seu pai Taímo. Este tinha vários sonhos, recebia notícias dos antepassados por via dos sonhos. O sonho aparece de forma bastante significativa nas obras de Mia Couto, e nos seus romances o sonho aparece como uma forma de comunicação entre o terreno e o divino. Após o desaparecimento de Junhito, o filho mais novo de Taímo, todos mudaram, principalmente o velho Taímo, que foi entristecendo até cair no chão com o peso de uma folha. 
Cerimónia fúnebre foi na água, sepultado nas ondas. No dia seguinte, deu-se o que de imaginar nem ninguém se atreve: o mar todo secou, a água inteira desapareceu na porção de um instante. No lugar onde antes pairava o azul, ficou uma planície coberta de palmeiras. Cada uma se barrigava de frutos gordos, apetitosos, luzilhantes. Nem eram frutos, parecia eram cabaças de ouro, cada uma pesando mil riquezas. Os homens se lançaram nesse vale, correndo de catanas na mão, no antegozo daquela dádiva. Então se escutou uma voz que se multiabriu em ecos, parecia que cada palmeira se servia de infinitas bocas (COUTO, 2007b, p. 20).

Na cerimônia do velho Taímo aconteceu algo estranho, o mar secou e nasceram palmeiras no lugar. Numa consulta a um feiticeiro, sobre o motivo da morte do velho Taímo, o feiticeiro disse que era preciso determinada cerimônia para sossegar o espírito do velho. Deveriam construir uma casa afastada e dentro dessa solitária residência deveriam colocar o velho barco de Taímo, com seu mastro e sua vela. Assim, o fizeram, todos ajudaram e levaram o barco para essa casa solitária. "À noitita, junto da fogueira, me explicaram a tradição. Motivo do barco, dentro da casa: meu pai poderia regressar, vindo do mar. E assim, todas as noites passei a levar para a casinha solitária uma panela cheia de comida. No dia seguinte, a panela estava vazia, raspadinha" (COUTO, 2007b, p. 21).

Kindzu precisava sossegar a morte de seu pai, que foi um morto que enlouqueceu, devido às coisas que se passaram na terra, às tantas atribulações e violências que a guerra deixou. "Primeiro, explicaram, eu devia era tratar o assunto de meu pai, sossegar sua morte. Enquanto eu não despedisse dele de boa maneira, a minha vida seria um indesatável novelo. Concordei. Mas como poderia vencer aquela raiva do falecido"? (COUTO, 2007b, p. 30). O espírito de Taímo sempre iria encontrar Kindzu. "A viagem mal começava e já o espírito de meu velho me perseguia" (COUTO, 2007b, p. 40).

Novamente, no segundo caderno de Kindzu, "Uma cova no teto do mundo", vai reaparecer o assunto da cerimônia do velho Taímo. Kindzu tem um encontro com o espírito de seu pai, o qual lhe fala sobre os sofrimentos, a falta de cerimônia na sua morte. 
Kindzu sofria por não ter cumprido a tradição; ele deixou sua casa e foi andar pelo mundo, ninguém mais prestou cerimônias ao falecido Taímo, ninguém levou comida e bebida.

- Vou ajudar a acabar com essa guerra. Me acredita, pai.

Ele sorriu, desprezador. Eu, se me pensava esperto, não descobrira a razão da vida estar a correr às mil porcarias? Tudo aquilo era castigo encomendado por ele, meu legítimo pai. Minhas desavenças, os tropeços que sofria, provinham de eu não ter cumprido a tradição. Agora, sofria castigos dos deuses, nossos antepassados. Lamentavase da cansativa morte:

- Sou um morto desconsolado. Ninguém me presta cerimónias. Ninguém me mata a galinha, me oferece uma farinhinha, nem panos, nem bebidas. Como posso te ajudar, te livrar das tuas sujidades? Deixaste a casa, abandonaste a árvore sagrada. Partiste sem me rezares. Agora, sofres as consequências. Sou eu que ando a ratazanar teu juízo.

- Mas, pai, durante todos os dias eu te levava comida...

- Nas primeiras noites, sim. Depois, nunca mais eu vi nada de comer. Só a panela vazia, mais nada.

- Alguém comia...

— Ninguém toca em prato de defunto. (COUTO, 2007b, p. 44-45)

A sombra do velho Taímo pesava sobre Kindzu. A terra se encontrava da mesma forma, estava em divórcio com os antepassados. No oitavo caderno de Kindzu, "Lembranças de Quintino”, também aparece um fato relacionado à falta das cerimônias devidas no momento da morte: "Quintino sorriu, mais cheio de susto que vontade. Ele sabia: os recém-falecidos recusam sair deste mundo se não lhes dedicam as devidas cerimónias. Ele bem que tinha dito à senhora: era bom despedir do patrão, organizar as cerimónias" (COUTO, 2007b, p. 145).

No décimo capítulo, “A doença do pântano”, momento em que Tuahir já está bastante debilitado, fala com Muidinga sobre a morte: “- Se eu falecer aqui não me enterre no matope. - O tio não vai morrer. - Você não sabe nada. Vou-lhe dizer: quem morre enterrado no lodo se transforma em peixe" (COUTO, 2007b, p. 178).

A morte é uma constante nas obras de Mia Couto. Esta aparece de forma frequente em seus romances, pois em África as pessoas não morrem definitivamente, mas continuam 
a transitar e estar presentes entre os vivos. É preciso todo um cuidado com as cerimônias devidas aos mortos, caso contrário, os espíritos vão perseguir os vivos.

A circulação da força vital, representada pela morte, caracteriza toda a África como princípio vital, segundo o qual, a morte não é ruptura, é uma mudança de vida, uma travessia, digamos assim, para um outro ciclo de vida e, é por isso, que os mortos entram na categoria dos ancestrais, dos protetores, dos guardiões dos vivos, enfim, são venerados como espíritos superiores (OTINTA, 2008, p. 111).

Em outro romance de Mia Couto, Um rio chamado tempo, uma casa chamada terra, as cerimônias fúnebres ocupam lugar de destaque na narrativa. Depois de anos de ausência, o estudante Marianinho volta a Luar do Chão, incumbido de realizar as cerimônias da morte de seu avô Mariano. Em vários trechos da narrativa, o autor descreve detalhes das cerimônias e as questões do luto. "Mesmo ao longe já se nota que tinham mandado tirar o telhado da sala. É assim, em caso de morte. O luto ordena que o céu se adentre nos compartimentos para limpeza das cósmicas sujidades. A casa é um corpo - o tecto é o que separa a cabeça dos altaneiros céus" (COUTO, 2003, p. 28-29). A morte é vista como um nascimento: “Em África, os mortos não morrem nunca. Excepto aqueles que morrem mal. A esses chamamos de 'abortos'. Sim, o mesmo nome que se dá aos desnascidos. Afinal, a morte é um outro nascimento" (COUTO, 2003, p. 30).

Há vários fenômenos sobrenaturais que são explicados pela onipresença dos espíritos. "Os laços entre os defuntos e os vivos têm lugar naturalmente e aqueles intervêm sem cessar no desenrolar dos acontecimentos, protegendo os vivos, ou punindo-os quando estes se esquecem de venerá-los” (FERREIRA, 2007, p. 370). São vários mitos e crenças que povoam o universo dos personagens.

Em quase todos os textos de Mia Couto regista-se um fatalismo místico, ritualista, intimamente relacionado com os arquétipos mentais das comunidades tradicionais. As superstições e as profecias, que povoam o universo das personagens, concorrem para criar um imaginário determinado e também para aprofundar os sintomas da inexorabilidade do seu destino (FERREIRA, 2007, p. 371). 
Além do tema da tradição, a morte também é marcante nas narrativas de Mia Couto por conta do contexto social e político que assolou Moçambique por muitos anos. Suas personagens vivem entre o sonho e a realidade, a vida e a morte; são seres excepcionais e cheios de esperança. Num clima de catástrofes naturais e de um contexto político e econômico marcado por sofrimentos e angústias, a morte, por situar-se no espaço do sagrado, dá sentido à existência daquele povo.

Pela visão mítica e sagrada da morte, concebida como mais um momento na existência do ser humano em que este acede a um estatuto mais elevado e passa a pertencer ao conjunto dos residentes permanentes do inconsciente colectivo, as personagens de Mia Couto recusam o seu dramatismo, evidenciando o seu potencial de renovação, promessa de uma nova vida, mais feliz e mais justa, de um renascimento individual e colectivo que fomenta a esperança no futuro (FERREIRA, 2007, p. 411).

Essa esperança de um futuro aparece nas obras Terra Sonâmbula e $A$ varanda do Frangipani. Muidinga e Tuahir, assim como os velhos do asilo acreditam que o país vai se renovar e buscam por meio do sonho uma vida mais digna. Muidinga e Tuahir caminham sem saber para onde, caminham em círculos, mas por meio dos cadernos de Kindzu emergem na fantasia e no sonho, estão à procura de algum caminho, de encontrar alguém, esperam que a paisagem se transforme, que as cinzas e poeiras se tornem verdes, estão à procura do mar. Os velhos do asilo, mesmo estando vivendo naquele lugar isolado, longe de tudo e de todos, sabem que estão próximos da morte, ainda sonham com uma morte digna.

Segundo Ferreira (2007), a morte que permeia os romances de Mia Couto vai muito além da morte física. "Os romances do autor moçambicano versam, sobretudo, uma outra morte, permanente, insidiosa: a que sofre a própria terra moçambicana, vítima da guerra, da fome, da corrupção e do aniquilamento cultural” (FERREIRA, 2007, p. 412). E em meio a esse ambiente de morte, surgem os velhos e os ensinamentos das tradições, o sonho e a esperança, um mundo povoado de deuses e espíritos que guiam os caminhos dos homens. 
A morte simboliza não apenas uma pessoa, mas toda a nação. Em Terra Sonâmbula, no capítulo "A lição de Siqueleto", a morte de um velho não é descrita apenas como a morte de um indivíduo, mas como a extinção de toda uma nação. A forma de lutar contra aquela guerra era simplesmente ficar vivo, resistir até o fim para que a tradição não se acabasse.

Era por causa do cansaço que ele não abria os dois olhos de uma só vez. O idoso homem tinha, apesar de tudo, seus pensamentos futuros. Para ele só havia uma maneira de ganhar aquela guerra: era ficar vivo, teimando no mesmo lugar. Não desejava nenhuma felicidade, nem sequer se deliciar com doces lembranças. Lhe bastava sobreviver, restar como um guarda daquela aldeia em ruínas. Agora ele amaldiçoa os que tinham saído dali (COUTO, 2007b, p. 66).

Também em Um rio chamado tempo, uma casa chamada terra, a morte não simboliza apenas um indivíduo, mas um coletivo.

Esta terra começou a morrer no momento em que começamos a querer ser outros, de outra existência, de outro lugar. Luar-do-Chão morreu quando os que a governaram deixaram de a amar. Mas a terra não morre, nem o rio se suspende. Deixe, o chão voltará a abrir quando eu entrar, sereno, na minha morte. (COUTO, 2003, p. 195)

Em A varanda do Frangipani, a personagem Marta Gimo, em conversa com o policial Izidine Naíta também alertava sobre a morte que deveria ser investigada: a morte que estava acontecendo naquele asilo, não apenas a morte do inspetor ou a morte daqueles velhos, mas a morte de toda uma nação.

— Escute, senhor inspector: o crime que está sendo cometido aqui não é esse que o senhor anda à procura.

- $\mathrm{O}$ que quer dizer com isso?

- Olhe para estes velhos, inspector. Eles todos estão morrendo.

- Faz parte do destino de qualquer um de nós.

- Mas não assim, o senhor entende? Estes velhos não são apenas pessoas.

- São o quê, então?

- São guardiões de um mundo. É todo esse mundo que está sendo morto. (COUTO, 2007a, p. 36) 
O policial Izidine não era capaz de compreender essa morte, ele era da cidade, um de fora, não conhecia a tradição, só entendia de morte física, aliás, ele estava naquele asilo para investigar a morte física de Vasto Excelêncio. Mas naquele asilo a morte não atingia apenas o material. "Esta é a verdadeira morte, definitiva e irreversível. Enquanto a morte atinge apenas o indivíduo, a aparência, a vida continua; mas quando ela atinge o grupo e a sua coesão, a sobrevivência é definitivamente ameaçada” (FERREIRA, 2007, p. 415).

A relação entre os vivos e os mortos é recíproca, os mortos só “ajudam” os vivos que agem com respeito e realizam os rituais e cerimónias, sempre os lembrando. Isso fica evidente em Terra Sonambula, pois Kindzu começa a ser perseguido por seu pai quando deixa sua terra e deixa de realizar os rituais com seu pai.

É necessário respeitar a tradição, relembrar os antepassados, para se construir uma nação livre, sem misérias e sofrimentos.

Esta é, no fundo, a tese que Mia Couto desenvolve em todos os seus romances: Kindzu, isto é, o moçambicano do presente, tem que procurar o seu caminho em íntima relação com os antepassados e seus ensinamentos. Só assim poderá construir uma nação nova, livre da miséria e do sofrimento que a têm marcado e que são consequência do afastamento dos moçambicanos em relação aos seus antepassados, isto é, em relação a uma matriz cultural que os faça recuperar as suas raízes (FERREIRA, 2007, p. 422).

Em A varanda do Frangipani, as histórias dos velhos do asilo são marcadas pela morte. Cada velho vai narrar sua versão sobre a morte de Vasto Excelêncio. Antes de iniciar o relato sobre o inspetor assassinado, os velhos relembram tempos passados, em que também estão presentes acontecimentos relacionados a mortes. É assim que se constroem as narrativas de Mia Couto, nessa permeabilidade entre o mundo dos vivos e o mundo dos mortos. Os mais novos devem respeitar um mundo tradicional que é regido pelas leis dos antepassados. Em $A$ varanda do Frangipani, Izidine cumpre a sua missão "não porque descobre o tráfico de armas por detrás da morte de Vasto Excelêncio, mas porque percebe, finalmente, 
a importância de preservar a vida e a sabedoria daqueles velhos, de não os deixar morrer sem fazer vivificar o legado de uma identidade, a sua" (FERREIRA, 2007, p. 447).

A morte é uma das consequências da guerra, mas essa morte não é algo natural, e sim trágico, que gera angústia e medo, causando desequilíbrio nos ciclos naturais da existência humana. Mito e realidade povoam as obras de Mia Couto, as várias mortes presentes nas narrativas, a morte de Junhito, a nação jovem; a morte dos velhos do asilo, a morte da tradição; a morte sem cerimónia de Ermelindo Mucanga; a estrada morta, os mortos da guerra, mas há também a perspectiva de que esses mortos passem a conviver com seus ancestrais.

Há, na cultura africana e no seu imaginário, uma espécie de força energética, um misticismo que liga todos os seres às divindades ancestrais. A perspectiva hierárquica do mundo situa os deuses no topo da hierarquia, seguida dos mortos, dos vivos e dos outros seres viventes. A morte não assume uma dimensão trágica, como acontece nas sociedades ocidentais, mas é perspectivada como uma mudança de ciclo, como transformação e como regresso ao mundo dos espíritos (GOMES, 2016, p. 112).

Nas sociedades africanas, a morte vai se afirmar como um fato sociocultural, e os rituais associados a ela buscam a unificação da família e a expulsão dos medos e aflições. Pode-se dizer que a morte tem um significado religioso e sagrado, pois a ela "está associada a crença na continuidade da vida e da existência, num mundo invisível, onde moram os deuses e os espíritos dos falecidos. Estes espíritos interagem, permanentemente, com o mundo dos vivos e determinam o seu curso existencial” (GOMES, 2016, p. 113).

É importante salientar que essas mortes apresentadas nas narrativas são contadas por meio da oralidade. Em A varanda do Frangipani, é o próprio morto que reclama uma cerimónia digna. Em Terra Sonâmbula é o velho Taímo que vai contar a Kindzu sobre o motivo da perseguição. É por meio da voz de Muidinga que o velho Tuahir fica sabendo das mortes que perpassaram o caminho de Kindzu. Os mortos e os vivos estão entrelaçados nas narrativas. O universo narrativo de Mia Couto "é povoado de mortos e de vivos que interagem entre si, nem sempre de um modo harmonioso. O real e o sobrenatural 
coabitam de um modo natural e espontâneo, e a morte, como outro ciclo da vida, é, apenas, o prolongamento, a continuidade da existência" (GOMES, 2016, p. 114-115). A narrativa ficcional de Mia Couto é uma reflexão sobre a condição humana.

A obra de Mia Couto elege, de fato, a morte como uma das temáticas centrais. Esta eleição significa que a sua narrativa ficcional é, também, uma reflexão sobre a condição humana dos homens e mulheres moçambicanos. A experiência trágica da guerra desvelou a dimensão mais maléfica do ser humano, capaz de atrocidades impensáveis, praticadas contra outros seres humanos inocentes. As vítimas da história calaram-se para sempre, mas a literatura insiste em trazêlas de volta, dando voz ao seu sofrimento e aos seus lamentos (GOMES, 2016, p. 116).

A literatura, essa voz que não se cala, continua dando voz às várias mortes presentes na humanidade. Essas mortes narradas por Mia Couto poderiam ser apenas ficção, mas estão espalhadas por várias partes do universo. Guerras recentes, várias mortes, tanto físicas, quanto simbólicas estão presentes por toda a parte. Que essa voz ecoada pelos personagens de Mia Couto seja reflexo para o mundo: para que não haja tantas "mortes", é preciso respeito e conhecimento das tradições, da cultura, da sabedoria dos antepassados; que os vivos e os mortos sigam entrelaçados nesse mundo real e fictício.

\title{
TRAINING BETWEEN THE LIVING AND THE DEAD ON THE SONANGLE LAND AND THE FRANGIPANI VARANDA
}

\begin{abstract}
In this article we seek to present a reading of the works Terra Sonâmbula and the balcony of the Frangipani, by the Mozambican author Mia Couto, emphasizing the interlacing between the living and the dead, especially the funeral ceremonies. The two narratives bring instigating questions about ceremonies and the care that should be given to the dead. Death appears not only as a physical phenomenon, but as mystical and spiritual. It seeks to reflect how these perceptions of death are present in the Mozambican universe. As a theoretical contribution, we use the readings of Ferreira (2007), Gomes (2016) and Otinta (2008).
\end{abstract}

KEY WORDS: Ceremonies; Mia Couto; Deaths; Live. 


\section{REFERÊNCIAS}

COUTO, Mia. A varanda do Frangipani: São Paulo: Companhia das letras, 2007a. . Terra sonâmbula. São Paulo: Companhia das letras, 2007b. . Um rio chamado tempo, uma casa chamada terra. São Paulo: Companhia das letras, 2003.

FERREIRA, Ana Maria Teixeira Soares. Traduzindo mundos: os mortos na narrativa de Mia Couto. Tese (Doutoramento em Literatura) - Universidade de Aveiro, Aveiro, 2007.

GOMES, Manuel Tavares. Entre o sonho e a morte: desvelamentos, revelações e contaminações na narrativa ficcional de Mia Couto. Literatura e Sociedade. 2016. Disponível em: < http://dx.doi.org/10.11606/issn.2237-1184.v0i21p100-117>. Acesso em abr. 2018.

OTINTA, Jorge de Nascimento Nonato. Mia Couto: Memória e Identidade em Um rio chamado tempo, uma casa chamada terra. São Paulo, 2008. Dissertação de Mestrado - Programa de Estudos Comparados de Literaturas de Língua Portuguesa.

Recebido em: 26/08/2018.

Aprovado em: 01/12/2018. 